\title{
LA DEMOCRACIA LIBERAL FRENTE A LOS RETOS DEL MULTICULTURALISMO
}

Ana Regina Luévano*

RESUMEN: Se presenta la teoría liberal de Will Kymlicka como una posible solución teórica a los problemas que enfrentan el multiculturalismo y la representación política en las democracias; se ensaya su aplicación al problema de las minorías indígenas en México y se ofrecen críticas a dicha teoría liberal, en especial la de Ambrosio Velasco.

PALABRAS ClaVE: Kymlicka, multiculturalismo, democracia liberal, representación política, minorías indígenas.
ABSTRACT: In this article, we propose Will Kymlicka's liberal theory as a potential theotretical solution to the multicultural and political representation problems in democracies. This theory will be applied to Mexico's problem of native minorities and criticism regarding such liberal theory namely that of Ambrosio Velasco will be explored.

KEYWORDS: Kymlicka, multiculturalism, liberal democracy, political representation, native minorities. 


\title{
LA DEMOCRACIA LIBERAL FRENTE A LOS RETOS DEL MULTICULTURALISMO
}

\author{
If living together is impossible, \\ then life itself is impossible as well. \\ Miladin Zivotic
}

\section{Introducción}

Dogville, un pequeño pueblo de Estado Unidos, es el escenario sobre el cual se desarrolla la película-también llamada de esta manera- del director danés Lars Von Trier.* Sus habitantes, personas humildes entregadas al trabajo de campo, viven a lo largo de una breve calle, en donde las fronteras entre lo público y lo privado no existen, expuesta la vida de cada uno de sus miembros al juicio de los demás.

A este peculiar lugar llega Grace, protagonista de la cinta, en busca de ayuda y con la esperanza de tener un nuevo comienzo. Con la ilusión de encontrar una mejor calidad de vida

*2003, Dinamarca, Film i Vast (Nicole Kidman, Harriet Andersson, Lauren Bacall). y un hogar para establecerse, acepta las condiciones de los miembros de este pueblo para formar parte de ellos. Mujer dulce, amable y con un gran espíritu de servicio, logra que los pobladores de Dogville, tras celebrar una reunión de consejo y con la intercesión a su favor de uno de sus líderes, le abran las puertas de la comunidad. Sin embargo, aquella vida que en un principio parecía perfecta para la joven mujer, poco a poco se fue convirtiendo en un calvario, obligándola a padecer una serie de humillaciones con tal de seguir siendo parte del grupo. Víctima de los constantes abusos, tanto psicológicos como físicos y con el juicio nublado por el sufrimiento, Grace un día decide hacer justicia por su propia mano, dejando marcada su 
huella en cada uno de los miembros de Dogville.

La película pretende ser un reflejo del desprecio y desconfianza que se tiene ante lo diferente, lo otro, por parte de las diversas comunidades en Estados Unidos. Y justamente en estos casos se puede decir que la ficción se convierte en realidad. El drama de la cinta, hasta ahora descrito, logra traspasar la pantalla, dejando al descubierto el sufrimiento que padecen muchas de las personas que abandonan su país de origen en busca de una mejor calidad de vida y de nuevas oportunidades.

En los últimos años, la migración ha aumentado de manera alarmante y ha hecho de este fenómeno uno de los problemas más importantes en el desarrollo de la política internacional. Es un hecho innegable que en la actualidad la mayoría de los países son culturalmente diversos. Realmente son escasos aquellos cuyos ciudadanos comparten el mismo idioma o bien pertenecen al mismo grupo étnico-cultural. Esta diversidad ha puesto en riesgo la estabilidad de las instituciones democráticas y ha obligado a los teóricos liberales a replantearse algunos de sus principios básicos.

La propuesta de Will Kymlicka es una teoría liberal que intenta hacer frente a los problemas del multiculturalismo y a los conflictos de la representación política en las demo- cracias. La exposición de la tesis de Kymlicka constituye la primera parte de la investigación. En una segunda parte se hará una breve revisión del concepto de representación política, noción clave para calificar las democracias liberales a partir de la teoría multicultural de Kymlicka.

En una tercera parte se analizará uno de los retos multiculturales a los que se enfrenta actualmente México: las minorías indígenas. En esta misma sección, se analizarán las condiciones de posibilidad para la aplicación de la tesis de Kymlicka en el problema concreto de México, así como las ventajas y desventajas de dicha teoría.

Por último, en una cuarta parte y a manera de conclusión, se exponen una serie de comentarios finales que recogen algunas de las críticas hechas a la teoría de Kymlicka, como la del filósofo mexicano Ambrosio Velasco.

\section{Liberalismo y multiculturalismo}

Históricamente, se ha pensado que otorgar derechos diferenciados en favor de un grupo puede ser contradictorio a los derechos individuales defendidos por el liberalismo. Los principios fundamentales de la democracia liberal, al exigir una igualdad de derechos entre todos los sujetos, excluyen la posibilidad de resolver 
las demandas multiculturales del reconocimiento político de las diferencias sociales y culturales entre los diversos grupos que conforman una sociedad. ${ }^{1}$ Ante esta situación, la primera pregunta que surge es si las democracias liberales pueden proporcionar o no un marco institucional adecuado para el multiculturalismo.

La respuesta abrió un debate entre dos grupos. Por un lado, se encuentra la postura de los comunitaristas, encabezados por Charles Taylor; por otro lado, las tesis de la democracia liberal.

Para los comunitaristas, la ciudadanía homogénea-característica de la democracia liberal- implica el desconocimiento de derechos diferenciados de grupos culturales, que son indispensables para el efectivo ejercicio de su libertad individual. Por esta razón, el reconocimiento de derechos especiales exige la aplicación de una ciudadanía diferenciada. Las posiciones que defienden una ciudadanía homogénea dan prioridad a la persona individual sobre el grupo o comunidad; por ello, se les identifica con el liberalismo. Las posiciones que defienden una ciudadanía diferenciada dan prioridad a las necesidades comunitarias frente a las preferencias de los individuos.

${ }^{1}$ Cfr. Ambrosio Velasco, "Multiculturalismo liberal y Republicano", http://www.ses.unam.mx/ curso2008/pdf/Velasco.pdf, p. 4.
Este debate entre comunitaristas y liberales ha contribuido a radicalizar el dilema y las controversias, en vez de esclarecer el problema del multiculturalismo. En esta discusión, algunos pensadores liberales como Will Kymlicka han desarrollado una visión liberal del multiculturalismo:

La discusión sobre la primacía del individuo o de la comunidad es una vieja y venerable discusión en filosofía política. Pero debiera quedar claro, espero, cuán poco útil resulta para evaluar la mayoría de los derechos diferenciados de grupo en las democracias occidentales. La mayoría de estos derechos no se refiere a la primacía de la comunidad sobre los individuos. Más bien se basan en la idea de que la justicia entre grupos requiere que los miembros de los diferentes grupos se pongan de acuerdo sobre sus diferentes derechos. ${ }^{2}$

Uno de los principales objetivos de Kymlicka es desarrollar una teoría liberal de los derechos de las minorías. Es verdad que "las sociedades modernas tienen que hacer frente, cada vez más, a grupos minoritarios que exigen el reconocimiento de su identidad". ${ }^{3}$ Esto es, precisamente,

${ }^{2}$ Will Kymlicka, Multicultural Citizenship. A liberal theory of minority rights, 1996, México, FCE, trad. Carmen Castells Auleda, p. 47.

${ }^{3}$ Kymlicka, op. cit., p. 13. 
lo que implica el reto del multiculturalismo.

Dando una respuesta a este desafío, propio de las sociedades modernas, y sin dejar de lado los principios liberales, la teoría que propone se fundamenta en dos premisas básicas. La primera apoya la idea de que la libertad individual está relacionada con la pertenencia al propio grupo nacional. En otras palabras, Kymlicka propone que la construcción de la identidad personal está determinada por el grado de identificación que una persona tiene respecto a su grupo. El conjunto de creencias y principios, que forman parte del ideario del grupo, influyen directamente en el proyecto de vida de cada miembro, así como en la elección de los medios indicados para llevarlo a cabo.

La segunda busca que los derechos específicos, en función del grupo, puedan fomentar la igualdad entre la minoría y la mayoría. Por medio de la identidad individual, basada en la pertenencia a un grupo que le reconoce como miembro, es posible establecer los puentes de unión con el resto de los miembros de la sociedad que conforman la mayoría.

Estas dos premisas, sobre las cuales se construye la teoría de Kymlicka, están enfocadas a responder a dos demandas de derechos colectivos o de grupo: las "restricciones internas" y las “protecciones externas". Mediante las primeras se imponen una serie de limitaciones a las libertades civiles y políticas de los miembros de la comunidad. Tales restricciones internas son inaceptables para Kymlicka. Por el contrario, las protecciones externas buscan proteger la existencia e identidad de los diferentes grupos culturales limitando la influencia de las decisiones de la sociedad en general. ${ }^{4}$

A partir de estas dos premisas, Kymlicka pretende dejar de lado aquellas críticas que algunos liberales han hecho a la aceptación de los derechos específicos en función del grupo, apelando -erróneamente- a que dichos derechos se contraponen al compromiso liberal con la libertad individual.

Muchos de estos liberales llegaron a considerar que, por medio del establecimiento de derechos humanos universales - como la libertad de expresión, asociación y conciencia-, ya no era necesario el reconocimiento de derechos específicos de grupos minoritarios. Sin embargo, tal y como señala Kymlicka:

Cada vez está más claro que los derechos de las minorías no pueden subsumirse bajo la categoría de derechos humanos. Las pautas y procedimientos tradicionales vinculados a los derechos humanos son simple${ }^{4}$ Cfr. Velasco, op. cit., p. 5. 
mente incapaces de resolver importantes y controvertidas cuestiones relativas a las minorías culturales como las siguientes: ¿qué lenguas deberían aceptarse en los Parlamentos, burocracias y tribunales? ¿Se deberían dedicar fondos públicos para escolarizar en su lengua materna a todos los grupos étnicos y nacionales? ¿Se deberían trazar fronteras internas (distritos legislativos, provincias, Estados) tendentes a lograr que las minorías culturales formen una mayoría dentro de una región local? ¿Debería devolver poderes gubernamentales el nivel central a niveles locales o regionales controlados por minorías concretas, especialmente en temas culturalmente delicados como la inmigración, las comunicaciones y la educación? ¿Deberían distribuirse los organismos políticos de acuerdo con un principio de proporcionalidad nacional o étnica? ¿Se deberían conservar y proteger las zonas y lugares de origen tradicionales de los pueblos indígenas para su exclusivo beneficio, protegiéndolas de la usurpación de los colonos o de los explotadores de recursos? ¿Qué grado de integración cultural puede exigirse de los inmigrantes y los refugiados antes de que adquieran la ciudadanía? ${ }^{5}$

La mayoría de las doctrinas tradicionales sobre los derechos humanos dan una respuesta errónea a tales

${ }^{5}$ Kymlicka, op. cit., p. 18. problemas, y a menudo, ni siquiera las llegan a considerar dentro de sus propuestas. Para resolver estas cuestiones es necesario complementar la doctrina de los derechos humanos con una teoría de los derechos de las minorías. Para Kymlicka, un Estado multicultural ideal debe contar con una teoría de la justicia omnicomprensiva, que incluya tanto derechos universales, asignados a los individuos independientemente de su pertenencia a un grupo, como ciertos derechos diferenciados de grupo, en reconocimiento especial de las culturas minoritarias.

Precisamente, el objetivo de Kymlicka es encontrar la manera en la que los derechos de las minorías pueden coexistir con los derechos humanos universalmente reconocidos, y también cómo los derechos de las minorías están limitados por los principios de libertad individual, democracia y justicia social.

Cabe señalar que, al hablar de multiculturalismo, es necesario establecer ciertos límites, pues no es posible agrupar todas las demandas de las minorías en un problema multicultural. Existen diferentes formas mediante las cuales los diferentes grupos culturales se incorporan en las comunidades políticas. Por un lado, explica Kymlicka, las minorías multiculturales se incorporan por medio de la inmigración voluntaria de in- 
dividuos y familias. Y, por otro, se pueden constituir también mediante la conquista o colonización de una sociedad que anteriormente gozaba de autogobierno y un territorio propio, de manera tal que constituía un Estado autónomo. Dependiendo de la manera en que se constituyan estos grupos en una sociedad, las demandas de cada uno de ellos tendrán distintos objetivos.

Las principales demandas de las minorías nacionales, por ejemplo, están enfocadas al reconocimiento de una forma de autogobierno o de una autonomía que les permita seguir siendo una sociedad diferente a la mayoritaria. Asimismo, su principal objetivo es convertirse en una nación separada y autogobernada paralela a la sociedad de la que forman parte.

Los grupos étnicos -formados por grupos de inmigrantes- lo que desean es integrarse a la sociedad de la que forman parte y que se les acepte como miembros de pleno derecho. De este modo, su objetivo principal es modificar las instituciones y las leyes para que sean más abiertas a las diferencias culturales.

Es importante tomar en cuenta esta distinción entre los objetivos y las demandas de las minorías culturales, respecto a su origen, para poder entender y analizar los diferentes problemas sociales, políticos y eco- nómicos a los que se puede enfrentar un Estado.

\section{Representación política y democracia}

Al hablar de democracia es posible separarla en dos grandes grupos: la democracia directa y la representativa o indirecta. Históricamente, cada uno de estos grupos se identifica con una determinada época en el tiempo. Para los griegos, la democracia directa era la mejor manera de expresarse dentro de la polis. En palabras de Sartori, la polis era un laboratorio ideal para una experiencia limitada al ámbito de los puros y simples principios democráticos: no sólo las dimensiones de la ciudad antigua eran pequeñísimas, sino que los ciudadanos vivían en simbiosis con su ciudad, a la que estaban unidos en un destino común de vida y muerte. ${ }^{6}$ Sin embargo, el cambio en las sociedades, en cuanto a la extensión territorial y el crecimiento de la población, provocaron que el modelo directo se hiciera impracticable. La representatividad se hizo necesaria para el ejercicio democrático.

La democracia indirecta surge como algo necesario y también como correctivo de la democracia directa. Una primera ventaja del gobierno repre-

${ }^{6}$ Cfr. Giovanni Sartori, ¿Qué es la democracia?, 1987, Madrid, Taurus, p. 167. 
sentativo es que un proceso político totalmente entretejido de mediaciones permite evitar las radicalizaciones elementales de los procesos directos. La segunda ventaja es que, incluso sin participación total, la democracia representativa subsiste como un sistema de control y limitación del poder. Con el paso del tiempo, la representatividad logró solucionar algunas de las nuevas circunstancias, propias de las sociedades modernas. ${ }^{7}$ Por ello, la democracia representativa se identifica con la modernidad.

Uno de los rasgos característicos de las democracias modernas, también llamadas liberales, es el pluralismo. Así como para los antiguos el principio de la isonomía era el elemento clave de la democracia, tal como apuntaba Jenófanes; la génesis ideal para las democracias liberales está en el principio de diferenciación o pluralidad. En palabras de Rawls, ese pluralismo ha de considerarse como un punto a favor para el desarrollo de las democracias liberales y por ello ha de 1lamarse razonable. ${ }^{8}$

Si bien es cierto que esta pluralidad se ha visto como un elemento a favor para las democracias, también ha provocado que se cuestione el principio de representación política de

${ }^{7}$ Cfr. Sartori, op. cit., p. 172.

${ }^{8}$ Cfr. John Rawls, Political Liberalism, 2002, México, FCE, trad. Sergio René Madero Báez, tercera reimpresión, p. 54. todos los grupos que conforman una sociedad y no sólo la representación de una mayoría. Uno de los mecanismos que se han propuesto para poder alcanzar la representación de todos los grupos sociales es la ciudadanía diferenciada.

En una sociedad en donde se reconocen los derechos diferenciados en función del grupo, los miembros de los colectivos se incorporan a la comunidad política no sólo en calidad de individuos, sino también por medio del grupo, y sus derechos dependen en parte de su propia pertenencia. Estos derechos son los que caracterizan a lo que Kymlicka llama "ciudadanía diferenciada". 9

Para la mayoría de los liberales hablar de una ciudadanía diferenciada es una contradicción. Para ellos, la ciudadanía es, por definición, tratar a las personas como individuos con iguales derechos ante la ley. De ahí que algunos pensadores liberales como John Rawls afirmen que una sociedad en la que los derechos y las reivindicaciones "dependen de la filiación religiosa, de la clase social, etcétera... puede no tener ningún concepto de ciudadanía en absoluto; ya que este concepto tal y como lo empleamos, va unido al concepto de sociedad entendida como un sistema justo de

\footnotetext{
${ }^{9}$ Cfr. Kymlicka, op. cit., p. 240.
} 
cooperación en beneficio mutuo de las personas libres". ${ }^{10}$

La salud y la estabilidad de las democracias modernas, explican otros liberales, dependen tanto de la justicia de sus instituciones básicas, como de las cualidades y actitudes de sus ciudadanos; es decir: de su sentimiento de identidad y de cómo consideran a otras formas de identidad nacional, regional, étnica o religiosa que, potencialmente, pueden competir con la suya; de su capacidad de tolerar y de trabajar con personas distintas de ellos; de su deseo de participar en el proceso político para promover el bien público y de apoyar a las autoridades políticas responsables. Sin ciudadanos que posean estas cualidades la capacidad de progreso de las sociedades democráticas disminuye progresivamente. El ideal de la ciudadanía debe apuntar a la creación de un foro donde la gente lograra superar sus diferencias y pensara en el bien común de todos los ciudadanos.

Sin embargo, si se define a la ciudadanía diferenciada como la adopción de derechos específicos poliétnicos o de autogobierno en función del grupo, entonces prácticamente todas las democracias modernas reconocen algún tipo de derechos diferenciados y, por lo tanto, el concepto de ciudadanía

${ }^{10}$ John Rawls, "The Domain of the Political and Overlapping Consensus", New York University Law Review, 64/2, p. 241. es mucho más diferenciado y menos homogéneo de lo que suponen los expertos en teoría política. Kymlicka distingue tres formas de ciudadanía diferenciada: 1) los derechos de representación; 2) los derechos poliétnicos; y, 3) los derechos de autogobierno.

En términos generales, las reivindicaciones de derechos de representación de los grupos desfavorecidos son a favor de la inclusión. Los grupos que se sienten excluidos buscan que se les incluya en el grueso de la sociedad, y el reconocimiento y acomodación de su "diferencia" tiene como objetivo facilitar este proceso. Cabe aclarar que no es sencillo lograr identificar qué grupos deberían tener derecho a la representación. Según Kymlicka, hay dos criterios que logran hacer más sencillo este proceso: 1) los miembros del grupo están sometidos a desventajas sistemáticas en el proceso político; o, 2) los miembros del grupo tienen derecho al autogobierno. De estos dos criterios es más fácil poder distinguir a los grupos que tienen derecho al autogobierno; distinguir a aquellos que están sometidos a desventajas sistemáticas resulta más complicado.

Según Iris Marion Young, existen cincos formas de opresión que se convierten en desventajas sistemáticas: explotación, marginación, impotencia, imperialismo cultural, y 
violencia aleatoria y acoso motivado por aborrecimiento o temor al grupo. ${ }^{11}$ Según estas 'caras de la opresión' descritas por Young, el 80\% de la población en Estados Unidos formaría parte de algún grupo oprimido. Solamente los hombres blancos heterosexuales, relativamente bien situados, jóvenes y sanos quedarían fuera de los grupos oprimidos. Los defensores de la representación especial no hacen más que extender estos derechos a los grupos no territoriales que también los pueden necesitar, por ejemplo, las minorías étnicas, las mujeres y los discapacitados. En el caso de los derechos de autogobierno, la existencia de la comunidad política principal está más condicionada. Las minorías nacionales afirman ser pueblos distintos, con pleno derecho al autogobierno. Y aunque pertenezcan a un país mayor, no por ello renuncian a su derecho de autogobierno primigenio; más bien se trata de transferir algunos aspectos de sus competencias de autogobierno a los estamentos políticos generales, a condición de conservar otros poderes para sí.

\section{Minorías nacionales: el conflicto de los pueblos indígenas en México}

${ }^{11}$ Cfr. Iris Marion Young, La justicia y la política de la diferencia, 2000, Madrid, Cátedra, p. 261.
México es un campo de batalla de conflictos culturales. Al tiempo que tiene que luchar y velar por los derechos de los pueblos indígenas, debe arrostrar también los problemas y maltratos que sufren los migrantes mexicanos allende nuestras fronteras. Según la explicación de Kymlicka, los pueblos indígenas formarían parte de un grupo de minorías nacionales. Zapotecos, Mayas, Nahuas, Purépechas, Mixtecos, Yaquis, Kikapúes y Otomíes, son sólo algunos de los grupos que tienen una representación vigente en el territorio nacional y que forman parte del origen de nuestra cultura.

Tras la conquista española, la mayoría de los indígenas fueron relegados de sus tierras, costumbres y tradiciones hasta convertirse en una especie de "extranjeros" en su propia nación, cuando fueron ellos los primeros en darle un nombre y una historia a estas tierras. Después de cinco siglos se fueron convirtiendo en una minoría, víctima de una cultura dominante. No es extraño que hoy muchos de los jóvenes mexicanos, a consecuencia de la globalización, puedan sentirse más identificados con un joven australiano que con un indígena, a pesar de que ambos viven en el mismo país y tienen la misma credencial para votar. 
Ante la amenaza inminente de la desaparición de los usos y costumbres de los pueblos indígenas, fueron muchos los que alzaron la voz, exigiendo justicia para ellos. Las condiciones de extrema pobreza en la que viven, como su incapacidad para poder integrarse a la sociedad, obligaron a las autoridades locales e internacionales a poner una solución a tal situación.

Así, surge la Declaración de las Naciones Unidas sobre los derechos de los pueblos indigenas. Dicha declaración es el producto de un largo proceso, iniciado en los años 70, cuando la Subcomisión para la Prevención de Discriminaciones y Protección de las Minorías, del Consejo Económico y Social, órgano principal de la Organización de las Naciones Unidas (ONU), recomendó la elaboración de un estudio que abordara el tema de los pueblos indígenas del mundo.

El objetivo primordial del documento es reconocer la autonomía que tienen estas comunidades en cuanto a grupo. Se menciona en el artículo cuarto de la Declaración, "los pueblos indígenas, en ejercicio de su derecho de libre determinación, tienen derecho a la autonomía o al autogobierno en las cuestiones relacionadas con sus asuntos internos y locales, así como para disponer de los medios para financiar de sus funciones autónomas". ${ }^{12}$

Este derecho emana de las características intrínsecas que los hacen ser un pueblo. Antes de la llegada de los españoles, las comunidades indígenas constituían una colectividad organizada y estructurada. Señala Luis Villoro:

Un pueblo sería, en principio, una colectividad que: 1) participa de una unidad cultural (lengua, creencias básicas comunes, ciertas instituciones sociales propias, formas de vida compartidas); 2) se reconoce a sí misma como una unidad, es decir, la mayoría de sus miembros aceptan su pertenencia a esa colectividad y son aceptados por ella; 3 ) comparten un proyecto de vida común, es decir, manifiesta la voluntad de continuar como una unidad y de compartir un futuro colectivo; $y, 4)$ está relacionada con un territorio geográfico específico. ${ }^{13}$

Las demandas de los pueblos indígenas son un claro ejemplo del tipo de demandas nacionales a las que se refiere Kymlicka. Admitir derechos especiales de protección para los miembros de ciertos grupos -tales como

${ }^{12}$ Artículo 4, Declaración de las Naciones Unidas sobre los derechos de los pueblos indigenas, 2008, México, Comisión Nacional para el Desarrollo de los pueblos indígenas, pp. 21-24.

${ }^{13}$ Luis Villoro, Estado plural, pluralidad de culturas, 1999, México, Paidós-UNAM, p. 85. 
los derechos de representación de grupos minoritarios, los derechos de autogobierno o los "derechos poliétnicos" para minorías religiosas o culturales, que los exentan del cumplimiento de ciertas leyes generales, o que reciben fondos especiales-implica reconocer una ciudadanía diferenciada dentro de un estado nación y con ello se abandona el principio liberal de igualdad de derechos y de una ciudadanía homogénea.

Aunque Kymlicka acepta la posibilidad de una ciudadanía diferenciada, cuestionando así el ideal liberal de una ciudadanía homogénea, se mantiene en una tradición liberal, pues rechaza totalmente la posibilidad de una confrontación entre derechos individuales y colectivos.

Al publicar la Declaración se logró el reconocimiento de las comunidades indígenas como pueblos autónomos y con ello fue posible, también, revivir muchas de sus tradiciones usos y costumbres, sepultadas bajo las categorías de una cultura occidental dominante. Sin embargo, algunos de ellos causaron gran revuelo en la sociedad, abriendo así un nuevo debate. ¿Se pueden permitir ciertas prácticas, apelando a una tradición cultural, que afecten las garantías individuales de las personas?

Es sabido que, en ciertas zonas de la sierra de Guerrero, habitadas en su mayoría por comunidades indígenas, mujeres y niñas son "vendidas" por dotes matrimoniales. Esta práctica se justifica apelando a una serie de costumbres y tradiciones que tienen cientos de años. A pesar del respaldo histórico y cultural con el que esta acción cuenta, es un acto inadmisible que pasa por encima de la dignidad de las mujeres. Si bien es cierto que es necesario defender los derechos de los pueblos indígenas, su capacidad de autogobierno y la permanencia de sus instituciones, sus usos y costumbres, deben existir también ciertas restricciones.

Los derechos en favor de las minorías, explica Kymlicka, deben cumplir con ciertas condiciones, a saber:

a) Los derechos de las minorías no deberían permitir que un grupo dominase a otros grupos.

b) Tampoco deberían permitir que un grupo oprimiese a sus propios miembros. En otras palabras, los liberales deberían intentar asegurar que existe igualdad entre los grupos, así como libertad e igualdad dentro de los grupos.

En pocas palabras, los pueblos indígenas tienen derecho a promover, desarrollar y mantener sus propias instituciones, costumbres y tradiciones -de una generación a la otra-, siempre y cuando estén en conformi- 
dad con las normas internacionales de derechos humanos. ${ }^{14}$

Al parecer, el debate originado a partir del reconocimiento de derechos diferenciados a favor de los pueblos indígenas ha quedado resuelto. En teoría esto es algo evidente y -hasta cierto punto-fácil de resolver, sin embargo, en la práctica, la realidad se torna distinta. A pesar de que los pueblos indígenas sean grupos que viven de manera paralela al Estado, tienen que subordinarse a ciertos principios que forman parte de una tradición democrática y liberal, aceptada por la mayoría. La situación se agrava cuando nos damos cuenta que muchos de los pueblos indígenas siguen siendo comunidades cerradas, monolingües $\mathrm{y}$, por tanto, desconocen las normas internacionales, de manera tal que no se dan cuenta de que sus garantías individuales son atropelladas.

Según el ejemplo que se acaba de exponer, parece que la propuesta de Kymlicka no alcanza a resolver los problemas de las minorías nacionales en México. Si bien lo que busca es un punto de equilibrio entre los derechos colectivos frente a los derechos individuales, su postura sigue inclinándose hacia los principios liberales, que dan prioridad al individuo sobre la comunidad.

Esta prioridad del individuo sobre la comunidad impide - hasta cierto

\footnotetext{
${ }^{14}$ Cfr. Artículo 34, Declaración..., op. cit, p. 38.
}

punto y en algunos casos- que la aplicación de su teoría se pueda realizar de manera efectiva en México. Si se acepta el punto liberal de Kymlicka tendríamos que concluir que muchas de las demandas multiculturales, los derechos de autonomía y autogobierno (que apelan a ciertos usos y costumbres) que exigen los pueblos indígenas de México son incompatibles con los valores de la democracia; por ejemplo, la expulsión de un miembro de su comunidad por motivos religiosos, que se practica en ciertas comunidades de Chiapas, no puede ser aceptada bajo ninguna circunstancia.

Esto podría ser considerado como desventaja en la teoría de Kymlicka; sin embargo, en la reciente aprobación de las reformas constitucionales en materia de derechos indígenas y con la publicación de la Declaración de las Naciones Unidas, la conclusión a la que llegaron los legisladores fue muy semejante a la propuesta de Kymlicka: reconocer derechos diferenciados a favor de un grupo no implica la dominación de ciertos grupos, ni tampoco la opresión de los individuos dentro de un grupo. Tal es el caso de las mujeres vendidas en las comunidades indígenas en Guerrero.

Frente a este problema multicultural, México ha dado un primer paso al publicar la Declaración de las $\mathrm{Na}$ ciones Unidas para el desarrollo de los pueblos indigenas. La meta de tener 
una sociedad más justa, en donde todos los ciudadanos, hombres y mujeres, indígenas, no indígenas y demás miembros gocen y puedan ejercer toda su libertad y sus derechos básicos, se ve lejana aún.

\section{Comentarios finales}

La teoría de Kymlicka logra responder a algunos de los retos del multiculturalismo desde una tradición liberal.

Mediante dos tesis principales, la construcción de la identidad personal determinada por el grado de identificación que una persona tiene respecto a su grupo, y que los derechos específicos, en función del grupo, pueden fomentar la igualdad entre la minoría y la mayoría, logra encontrar un punto de equilibrio entre los principios de la democracia liberal, que enfatiza la homogeneidad cultural ciudadana y la libertad individual frente al poder público y el multiculturalismo.

Si bien Kymlicka cuestiona la idea liberal de igualdad de derechos, sigue inclinando la balanza hacia el liberalismo, otorgándole una preferencia al individuo sobre el grupo, pues rechaza totalmente la posibilidad de una confrontación entre derechos individuales y colectivos al desconocer a aquellos que implican restricciones internas. Tales demandas son comunes en los reclamos de los pueblos indígenas de México, sobre temas de religión, de elección de autoridades, de sanciones penales y de propiedad, entre otros. En estos ámbitos se han planteado conflictos entre decisiones comunitarias y derechos individuales. Para tales casos, la visión liberal de Kymlicka no nos daría una respuesta satisfactoria. Según Ambrosio Velasco, el planteamiento multicultural de Kymlicka no responde adecuadamente a las principales demandas de los pueblos indígenas en México, pues varias de ellas se ubicarían en lo que él llama restricciones internas, que amenazan derechos civiles y políticos de los individuos.

Sin embargo, al revisar la conclusión a la que llegaron los legisladores mexicanos al redactar la Declaración de las Naciones Unidas sobre los derechos de los pueblos indigenas, resulta muy semejante a la propuesta de Kymlicka. Sólo se pueden permitir ciertos usos y costumbres, como parte del derecho de autogobierno que tienen los pueblos indígenas, siempre y cuando no vayan en contra de los derechos humanos y civiles de los miembros del grupo. Esta resolución, expuesta en la Declaración, me parece bastante razonable, pues al final no se trata de hacer un análisis o un debate sobre si es más valioso el individuo o el grupo, sino defender los derechos de una persona en cuanto tal. Los dere- 
chos civiles y políticos de un individuo emanan de su condición de persona y no dependen del grupo. Si bien es cierto que un individuo nace inmerso en una sociedad sus derechos no dependen de la sociedad, sino que son reconocidos por ésta.

A pesar de esto, la postura de Velasco sigue siendo contraria a la de Kymlicka. Su propuesta, para responder a este dilema entre democracia y multiculturalismo, no estriba en buscar una mediación equilibrada o una negociación entre liberalismo y comunitarismo, tampoco en cambiar el concepto de derechos colectivos, sino en redefinir el concepto de democracia, recurriendo a la tradición política republicana.

La noción republicana de la democracia implica una concepción del origen y legitimidad del poder político y una forma de gobierno. Durante la época moderna, el republicanismo fue desarrollado principalmente por Maquiavelo, Guiciardini, Harrington, Jefferson, Rousseau, Tocqueville, entre otros. ${ }^{15}$

${ }^{15}$ Sobre el concepto de republicanismo véase el ensayo de Ambrosio Velasco "Republicanismo", en N. Rabotnikof, A. Velasco y C. Yturbe, La tenacidad de la política, 1995, México, Instituto de Investigaciones Filosóficas, UNAM, pp. 109-120. Ver también Luis Villoro, "Democracia comunitaria y democracia republicana", en Luis Villoro (coord.), Perspectivas de la democracia en México, 2001, México, El Colegio Nacional, pp. 9-42. Ambrosio Velasco Gómez, "Democracia liberal
Esta concepción republicana de la democracia coincide en algunos puntos con la democracia liberal. Por ejemplo, ambas mantienen en común el principio del origen popular del poder político mediante el sistema electoral, el principio de legalidad de los actos de gobierno y la división funcional de poderes. También se diferencia del modelo general de la democracia liberal en cuanto que la democracia republicana enfatiza el carácter social y plural de la representación política, esto es, que la estructura del poder legislativo debe reflejar proporcionalmente la pluralidad de clases y grupos sociales principales que efectivamente existen entre los gobernados.

Para Velasco, la democracia republicana y el multiculturalismo son compatibles y mantienen una relación de interdependencia entre sí. La democracia republicana requiere una amplia libertad pública, donde puedan expresarse y reconocerse la pluralidad de intereses y concepciones del mundo, provenientes de los diferentes grupos sociales y culturales que existen entre los habitantes de una nación. Libertad pública y pluralismo son condiciones esenciales de la democracia republicana, a diferen-

y democracia republicana", en Araucaria, Revista Iberoamericana de Filosofia Política y Humanidades, 1999, U. de Sevilla, año 1, núm. 1, p. 72-82. 
cia de la democracia liberal, que enfatiza la homogeneidad cultural ciudadana y la libertad individual frente al poder público. Por su parte, el multiculturalismo, a fin de promover un continuo diálogo e intercambio cultural entre los diferentes pueblos o grupos sociales, requiere de un espacio público donde los diversos grupos de ciudadanos puedan expresar y argumentar sus visiones del mundo y acordar mutuos reconocimientos respecto a sus derechos comunes y sus derechos específicos como miembros de un grupo o pueblo que forma parte de una nación multicultural. En este sentido, la democracia republicana constituye la forma de gobierno adecuada para responder al reto fundamental del multiculturalismo que plantea Kymlicka, que apoya "la idea de que la justicia entre los grupos requiere que los miembros de los diferentes grupos se pongan de acuerdo sobre sus diferentes derechos". ${ }^{16}$

Según lo anterior es posible concluir que la teoría de Kymlicka representa un aporte significativo para el multiculturalismo, pues logra trasladar ciertos principios del liberalismo a la discusión y desbloquear el debate entre liberales y comunitaristas. Sin embargo, esta democracia, a diferencia de la republicana, no logra ser una solución satisfactoria para los problemas multiculturales de países como México. 